\title{
Bacterial activity in cystic fibrosis lung infections
}

\section{Geraint B Rogers ${ }^{1,2}$, Mary P Carroll2, David J Serisier ${ }^{2,4}$, Peter M Hockey², Valia Kehagia ${ }^{2}$, Graeme R Jones ${ }^{3}$ and Kenneth D Bruce*1} Address: ${ }^{1}$ Department of Life Sciences, King's College London, London, UK, ${ }^{2}$ Cystic Fibrosis Unit, Southampton University Hospitals NHS Trust,
UK, ${ }^{3}$ Health Protection Agency, Southampton Laboratory, UK and ${ }^{4}$ The Adult Cystic Fibrosis Unit, Mater Adult Hospital, Brisbane, Australia

Email: Geraint B Rogers - geraint.rogers@kcl.ac.uk; Mary P Carroll - mary@cjwing.demon.co.uk; David J Serisier - David_Serisier@mater.org.au; Peter M Hockey - Peter.Hockey@pulmonology.co.uk; Valia Kehagia - valkeh@yahoo.com; Graeme R Jones - Graeme.Jones@suht.swest.nhs.uk; Kenneth D Bruce* - kenneth.bruce@kcl.ac.uk

* Corresponding author

Published: 0 I June 2005

Respiratory Research 2005, 6:49 doi:10.1 186/1465-9921-6-49

This article is available from: http://respiratory-research.com/content/6/1/49

(C) 2005 Rogers et al; licensee BioMed Central Ltd.

This is an Open Access article distributed under the terms of the Creative Commons Attribution License (http://creativecommons.org/licenses/by/2.0), which permits unrestricted use, distribution, and reproduction in any medium, provided the original work is properly cited.
Received: 27 August 2004

Accepted: 01 June 2005

\begin{abstract}
Background: Chronic lung infections are the primary cause of morbidity and mortality in Cystic Fibrosis (CF) patients. Recent molecular biological based studies have identified a surprisingly wide range of hitherto unreported bacterial species in the lungs of CF patients. The aim of this study was to determine whether the species present were active and, as such, worthy of further investigation as potential pathogens.
\end{abstract}

Methods: Terminal Restriction Fragment Length Polymorphism (T-RFLP) profiles were generated from PCR products amplified from I6S rDNA and Reverse Transcription Terminal Restriction Fragment Length Polymorphism (RT-T-RFLP) profiles, a marker of metabolic activity, were generated from PCR products amplified from I6S rRNA, both extracted from the same CF sputum sample. To test the level of activity of these bacteria, T-RFLP profiles were compared to RT-T-RFLP profiles.

Results: Samples from 17 individuals were studied. Parallel analyses identified a total of 706 individual T-RF and RT-T-RF bands in this sample set. 323 bands were detected by T-RFLP and 383 bands were detected by RT-T-RFLP (statistically significant; $P \leq 0.001$ ). For the group as a whole, I 45 bands were detected in a T-RFLP profile alone, suggesting metabolically inactive bacteria. 205 bands were detected in an RT-T-RFLP profile alone and 178 bands were detected in both, suggesting a significant degree of metabolic activity. Although Pseudomonas aeruginosa was present and active in many patients, a low occurrence of other species traditionally considered to be key CF pathogens was detected. T-RFLP profiles obtained for induced sputum samples provided by healthy individuals without CF formed a separate cluster indicating a low level of similarity to those from CF patients.

Conclusion: These results indicate that a high proportion of the bacterial species detected in the sputum from all of the CF patients in the study are active. The widespread activity of bacterial species in these samples emphasizes the potential importance of these previously unrecognized species within the CF lung. 


\section{Introduction}

The Microbiological analysis of clinical specimens has relied traditionally on cultivation prior to identification. However, recent genetic innovations promise to provide dramatic advances in diagnosis and fresh insights into infections that have previously been considered well characterised. The use of molecular biological approaches in clinical scenarios obviates the requirement for in vitro culture prior to analysis and so removes problems associated with microbial cultivation. In addition, these approaches are ideal for cases such as trauma where predicting the pathogen(s) responsible is challenging.

Molecular biological approaches have gained widespread acceptance for the study of bacterial communities in natural environments [reviewed in [1-3]]. Here, nucleic acids, extracted directly from samples, act as templates for PCR amplification of phylogenetically-informative ribosomal sequences using oligonucleotide primers "universal" for the Domain Bacteria. This means that no prior assumptions are made about the identity of species present. Bacterial community composition can then be assessed through sequence analysis of cloned ribosomal PCR products and by Terminal Restriction Fragment Length Polymorphism (T-RFLP) profiling [4,5].

Here, we focus on bacterial infections within the lungs of cystic fibrosis (CF) patients. There are more than 5,000 registered CF patients in the UK [6]. Although CF patient life expectancy has steadily increased, the mortality rate for patients aged between 26 and 30 years remains at around 50 per 1000 per year [7]. Mortality is primarily determined by repeated infective exacerbations. Ultimately, 80 to $95 \%$ of CF patients succumb to respiratory failure brought on by chronic bacterial infection and concomitant airway inflammation [8]. The characterisation of the bacteria present in the CF lung is critical if therapy is to be advanced. Moreover, we suggest that this strategy can benefit a diverse range of clinical scenarios.

Previous molecular biological studies have shown that the level of bacterial diversity in adult CF sputum was much higher than previously recognised [9-12] and that the communities detected were distinct. This contrasts sharply with wisdom informed by traditional screening of sputa that focuses on only a few pathogenic species including Pseudomonas aeruginosa, Staphylococcus aureus and the Burkholderia cepacia complex.

Moreover, many of the species detected were anaerobes often obligate - from within the genera Bacteroides, Eubacterium, Fusobacterium, Porphyromonas, Prevotella, Rothia and Veillonella. This agreed with earlier studies [13,14] and may be of particular relevance given the increased recognition of the importance of anaerobic growth in CF infec- tions [15]. In addition, many of the species identified, including Abiotrophia adiacens, Mycoplasma salivarium, Ralstonia taiwanensis, Rothia mucilaginosus and Staphylococcus hominis, had not been reported as previously isolated from CF sputum. Although the role of these species in lung pathogenesis has yet to be determined, the first step is to establish whether they are active within the CF lung. Although activity does not necessarily imply pathogenicity, it strongly suggests that further study is warranted.

Here, we assess the extent to which bacteria in sputum sampled from the CF lung were active by exploiting the difference in stability of DNA and RNA. As 16S rRNA is inherently unstable, it can be used to define intact, metabolically active bacterial cells [16] with bacterial metabolic activity inferred from the level of transcription of these sequences [17]. Reverse Transcription Terminal Restriction Fragment Length Polymorphism (RT-T-RFLP), performed in parallel with T-RFLP provides an accepted means of determining relative metabolic activity within communities [18]. T-RFLP and RT-T-RFLP analyse the same genetic sequence. The single difference is that in RTT-RFLP, complementary DNA (cDNA) copies, generated from $16 \mathrm{~S}$ rRNA, are used as the template instead of $16 \mathrm{~S}$ rDNA. Here, we wished to test the hypothesis that the majority of the species identified in the CF lung are active. To do this, two profiling approaches were used to study DNA and RNA extracted directly from the same clinical sample taken from $17 \mathrm{CF}$ patients. Further, the T-RFLP profiles generated from the $17 \mathrm{CF}$ sputa were compared to those generated from sputa obtained from 19 healthy, non-CF individuals.

\section{Materials and methods Clinical samples and preparation for nucleic acid extraction}

Sputum samples were collected from 17 adult CF patients attending Southampton University Hospital, with ethical approval granted by the Southampton Research Ethics Committee (067/01). 12 patients were suffering infective exacerbation at time of sampling, whilst five were considered to be stable. Ten volumes of RNAlater solution (Promega, Southampton, UK) were added to sputum samples immediately following collection following manufacturer's instructions. Prior to nucleic acid extraction, samples were prepared for nucleic acid extraction, using a series of washes and sputasol treatment as described previously [10].

\section{DNA and RNA extraction}

All reagents, glassware and plastics used in RNA work were DEPC-treated prior to use. RNA was extracted as follows: $0.75 \mathrm{ml}$ of Tri Reagent (Sigma-Aldrich, Dorset, UK) were added to approximately $0.2 \mathrm{ml}$ of each sample and vortexed for $1 \mathrm{~min}$. Samples were incubated at room 
temperature for $5 \mathrm{~min}$ prior to the addition of $0.2 \mathrm{ml}$ chloroform. Samples were vortexed for $15 \mathrm{sec}$. and incubated at room temperature for $5 \mathrm{~min}$. Phases were separated by centrifugation at $12,000 \times \mathrm{g}$ for $15 \mathrm{~min}$ at $4^{\circ} \mathrm{C}$.

\section{i) DNA extraction}

$0.3 \mathrm{ml}$ of $100 \%$ ethanol was added to precipitate the DNA from the lower phase. The sample was mixed by inversion, incubated at room temperature for $3 \mathrm{~min}$ and centrifuged at $12,000 \times g$ for $5 \mathrm{~min}$ at $4{ }^{\circ} \mathrm{C}$. The pellet was washed in $0.1 \mathrm{M}$ sodium citrate, $10 \%$ ethanol solution (during each wash the pellet was allowed to stand for at least $30 \mathrm{~min}$ ). Pellets were centrifuged at $12,000 \times g$ for 5 min at $4{ }^{\circ} \mathrm{C}$ and washed twice in $75 \%$ ethanol. The DNA was vacuum dried, with the pellet resuspended in $100 \mu \mathrm{l}$ $\mathrm{H}_{2} \mathrm{O}$ and stored at $-20^{\circ} \mathrm{C}$.

\section{ii) RNA extraction}

The upper phase was transferred to a fresh microfuge tube and $0.5 \mathrm{ml}$ of propan-2-ol were added. Samples were incubated for $10 \mathrm{~min}$ at room temperature and RNA was pelleted by centrifugation at $12,000 \times g$ for $10 \mathrm{~min}$ at $4^{\circ} \mathrm{C}$. The supernatant was removed and the RNA pellet washed once in $75 \%$ ethanol and re-pelleted by centrifugation at $7,500 \times \mathrm{g}$ for $5 \mathrm{~min}$ at $4^{\circ} \mathrm{C}$. Pellets were air-dried for 10 min, resuspended in $30 \mu \mathrm{l}$ distilled water and incubated for 10 mins at $55^{\circ} \mathrm{C}$. Purified RNA samples were stored as aliquots at $-70^{\circ} \mathrm{C}$.

Prior to reverse transcription, any residual DNA was removed using DNAseI (Epicentre, Madison, USA) in accordance with the manufacturer's instructions, with PCR amplification controls performed as appropriate.

\section{Reverse transcription}

Two universal bacterial primers were used, namely; $8 \mathrm{f} 700$ (5'-AGA GTT TGA TCC TGG CTC AG-3') and 920r (5'CCG TCA ATT CAT TTG AGT TT-3') [5,10]. cDNA was generated from the isolated RNA using 920r and AMV reverse transcriptase (Promega, Southampton, UK) in accordance with the manufacturer's instructions. Double stranded DNA was generated using $1 \mu \mathrm{l}$ of this CDNA as template in a $50 \mu \mathrm{l}$ PCR reaction containing both primers ( $8 \mathrm{f} 700$ and 920r). PCR products amplified were verified by Tris-acetate-EDTA (TAE)-agarose gel electrophoresis on $0.8 \%$ (wt/ vol) TAE-agarose gels stained in ethidium bromide $(0.5$ $\mathrm{mg} / \mathrm{L}$ ) with images, viewed on a UV transilluminator (Herolab, Wiesloch, Germany), captured by using a Herolab image analyzer with E.A.S.Y STOP win 32 software (Herolab).

\section{DNA quantification}

Extracted DNA and restricted PCR products (below) were quantified using a CytoFluor series 4000 multiwell plate reader (PerSeptive Biosystems, Foster City, USA) using the
PicoGreen DS DNA quantitation kit (Molecular Probes, Lieden, Netherlands) following the manufacturer's instructions.

\section{T-RFLP amplification and profiling}

PCR products for T-RFLP analysis were amplified using primers $8 f 700$ (labelled at the 5'end with IRD700) and 926r from c. $20 \mathrm{ng}$ of extracted DNA as previously described [10]. PCR products (c. $20 \mathrm{ng}$ ) were digested to completion using $1 \mathrm{U}$ of the restriction endonuclease $C f_{0} \mathrm{I}$, with $c .0 .7 \mu \mathrm{g}$ of T-RFLP PCR products were separated by length using a LI-COR IR2 automated DNA sequencer again as previously described [10]. The gels were analysed by using GeneimageIR v.3.56 (Scanalytics, Fairfax, USA). When profile data were assessed, only peaks of $\geq 0.1 \%$ of the total lane signal were classified as bands for further analysis. The positions of these individual bands were calculated in relation to microSTEP 15 a (700-nm) size marker (Microzone, Lewes, UK). A threshold of $\times 2$ was used as a means of identifying marked differences between T-RFLP and RT-T-RFLP band volumes.

\section{Band Quantification and calling}

The IR signal level produced by each band was determined using Phoretix 1D Advanced v.5.10, (Nonlinear Dynamics, Newcastle upon Tyne, UK). Due to the low volumes loaded, small errors could have lead to significant variations in band intensity. To avoid such errors, band volumes were determined as a percentage of the total band volume detected in each profile.

\section{Sputum from non-CF individuals}

Sputum production was induced in 19 healthy, non-CF individuals by the inhalation of nebulised saline for 5 min. Following nebulisation, subjects were asked to rinse their mouths thoroughly with water and blow their noses. Expectorated sputum was then collected and subjected to the same DNA extraction, amplification and profiling protocols employed for CF sputum analysis. Individuals were selected at random to provide sputum samples. Individuals that reported either acute or chronic respiratory problems were excluded.

\section{in silico sequence analysis}

Published bacterial 16S rRNA gene sequence data, stored at GenBank http://www.ncbi.nlm.nih.gov/entrez/ query.fcgi?db Nucleotide, were retrieved. MapSort (Wisconsin Package version 10.3; Accelrys) was used to predict the band sizes for T-RFLP analysis. Mapsort, which locates the position of restriction endonuclease recognition motifs in a given sequence, was used to determine the length (in bases) from the 5 ' end of primer 8f-700IR (see below) to the first cleavage position of the restriction endonuclease $C f o I$ in each $16 \mathrm{~S}$ rRNA gene sequence. This process was performed on all of the bacterial entries in the 
Genbank database that spanned the amplified region. In this way, it was possible to predict the length of T-RF bands generated from 853 separate phylotypes (data not shown).

\section{Statistical analysis}

For each of the bands that were detected in a T-RFLP or RTT-RFLP profile unaccompanied by a band in the corresponding RT-T-RFLP or T-RFLP profile, the frequency of unaccompanied detection was compared with the frequency of accompanied detection in the sample set as a whole. The ratio of unaccompanied detection to total detection was multiplied by unaccompanied detection. This was performed because relatively frequently detected bands, which were unaccompanied in a majority of instances, would otherwise appear less significant. A score $\geq 2$ was used as a threshold for the identification of bands that differed notably between their detection by the two techniques.

Hierarchical cluster analysis, with the Dice measure and Chi-square test using Yates correction (SPSS for Windows v.10.1, SPSS Inc., Chicago, USA) was used to construct a dendrogram representing level of similarity between the 34 bacterial community T-RFLP and RT-T-RFLP profiles studied here. Further, this process was used to compare the similarity of T-RFLP profiles generated from CF sputa with those generated from healthy, non-CF sputum.

\section{Role of the funding source}

The sources of funding of this study were not involved in experimental design and interpretation. No influence was exerted on the decision to publish.

\section{Results}

Electrophoretic gel images generated by T-RFLP and RT-TRFLP profiling from five sputum samples are shown in Figure 1. An example of the identification of individual bands within a region of electrophoretic profile is shown for corresponding areas of a T-RFLP and RT-T-RFLP profiles in Figure 2.

\section{T-RFLP and RT-T-RFLP profiling}

Parallel T-RFLP and RT-T-RFLP analysis was performed on 17 sputum samples. A total of 706 individual T-RF and RT-T-RF bands were detected in this sample set. Of these, 323 were detected by T-RFLP analysis and 383 were detected by RT-T-RFLP analysis. This difference in the number of bands detected was significant $(\mathrm{P} \leq 0.001$, Chisquare test, Yates correction). The number of bands detected in profiles generated from each individual sample is shown in Table 1.

The banding positions generated through T-RFLP and RTT-RFLP analysis were compared for each sample. 178 bands were detected in both a T-RFLP profile and the corresponding RT-T-RFLP profile (356 bands in total), 145 bands were detected in a T-RFLP profile but were absent in the corresponding RT-T-RFLP profile, and 205 bands were detected in an RT-T-RFLP profile but were absent in the corresponding T-RFLP profile.

Where a band of a given length was detected in profiles generated in a sample, it was present in both T-RFLP and RT-T-RFLP profiles in $33.7 \%$ of instances. In $27.4 \%$ of instances in was detected in the T-RFLP profile alone and in $38.8 \%$ of instances it was detected in the RT-T-RFLP profile alone.

The ratio of unaccompanied bands to total bands detected was multiplied by the number of unaccompanied bands detected. This process identified 7 band lengths with a score of $\geq 2$ in T-RFLP profiles, compared with 25 band lengths in RT-T-RFLP profiles. The only band from either group whose length corresponded to that of a recognised CF pathogen was 209 bases (B. cepacia complex) had a score of 2.0 in RT-T-RFLP profiles. No pattern was discerned between any of the other bacterial species whose predicted T-RF length corresponded with these bands. No band length had a score $\geq 2$ in both T-RFLP and RT-T-RFLP profiles.

The intensity of each of the T-RF bands detected was determined and placed in rank order (descending band volume) (Table 2, see additional file). The five highest rank ordered bands represented $39.5 \%( \pm 21.1), 14.4 \%( \pm 6.2)$, $8.6 \%( \pm 2.6), 5.8 \%( \pm 1.6)$, and $4.5 \%( \pm 2.0)$ of the total band signal in T-RFLP profiles respectively. For RT-T-RFLP profiles, the top five rank ordered T-RF bands represented $35.2 \%( \pm 19.4), 14.4 \%( \pm 6.9), 9.2 \%( \pm 3.3), 7.0 \%( \pm 2.9)$ and $4.7 \%( \pm 1.7)$, respectively.

Fifty five of the T-RF bands lengths detected by T-RFLP profiling were in the five most intense bands in one or more profile, compared with $53 \mathrm{~T}$-RF band lengths in RTT-RFLP profiling. T-RF bands of a given length were detected within the top five rank ordered positions of intensity in an average of 1.5 T-RFLP profiles and 1.6 RTT-RFLP profiles. Of the T-RF band lengths identified in this way, 26 were detected in the top five rank positions in T-RFLP profiles but not RT-T-RFLP profiles, whereas 25 were detected in the top five rank positions in RT-T-RFLP profiles but not in T-RFLP profiles.

In both cases, a T-RF band of 155 bases, corresponding to that produced by $P$. aeruginosa, was the most frequently detected band in the top five rank ordered positions, being detected in $8.2 \%$ and $9.4 \%$ of T-RFLP and RT-TRFLP profiles respectively. The second most commonly detected T-RF band length was also the same in both 


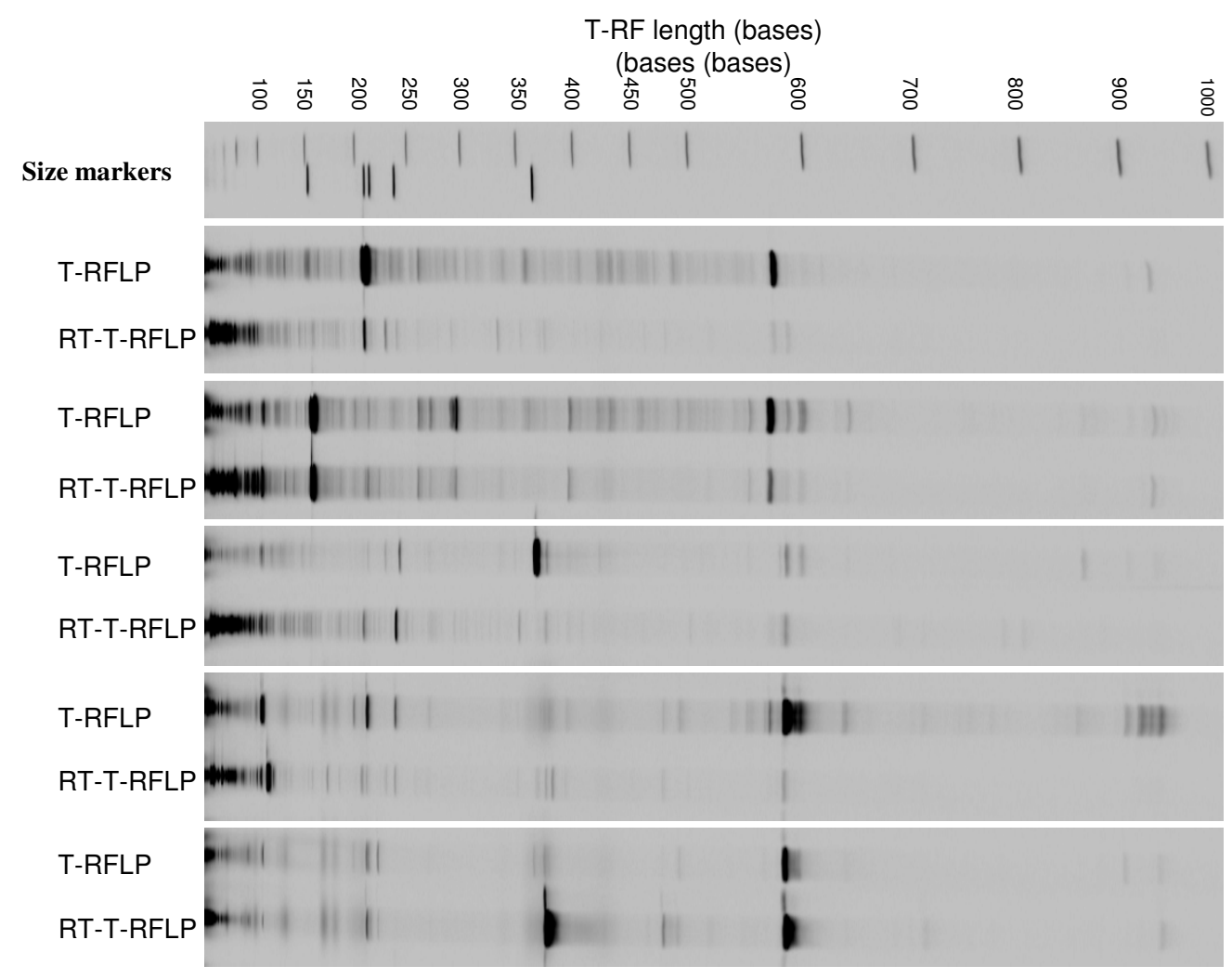

\section{Figure I}

Electrophoretic gel images generated by T-RFLP and RT-T-RFLP. This figure shows the profiles generated from five sputum samples within the sample set. By a process of automated comparison of band positions with those in marker lanes allows their length to be determined and direct comparisons to be made between lanes.

profiling approaches - a T-RF band of 78 bases in length was detected in one of top five rank ordered positions in $5.9 \%$ and $4.7 \%$ of T-RFLP and RT-T-RFLP profiles respectively. Computer-based band length predictions made using published sequence data indicate that a 78 base T$\mathrm{RF}$ band would be consistent with that produced by Ectothiorhodospira mobilis, Methylobacter psychrophilus, Methylomicrobium agile, Methylomonas rfodinarum and Methylomonas rubra.

The prevalence of other bacterial species that have been considered traditionally to be key CF pathogens was determined. In general, it was found that these were not highly represented in either the T-RFLP or RT-T-RFLP profiles. A band corresponding to B. cepacia complex was detected in one T-RFLP profile (patient 7), and one RT-T-RFLP profile (patient 2). These bands represented 2.2\% and 3.3\% of total band volume respectively. A band corresponding to $H$. influenzae, representing $1.7 \%$ of the total band volume, was detected in a single T-RFLP profile (patient 15). A band consistent with that produced by $S$. maltophilia was detected in the T-RFLP profiles generated from two patients (patients 1 and 2), representing 1.6\% and 5.5\% of the total band volume respectively. A band was also detected in the RT-T-RFLP profile from a third sample (patient 5), where it represented $18 \%$ of the total band volume. No band of a length corresponding to S. aureus was detected. 


\section{T-RFLP}
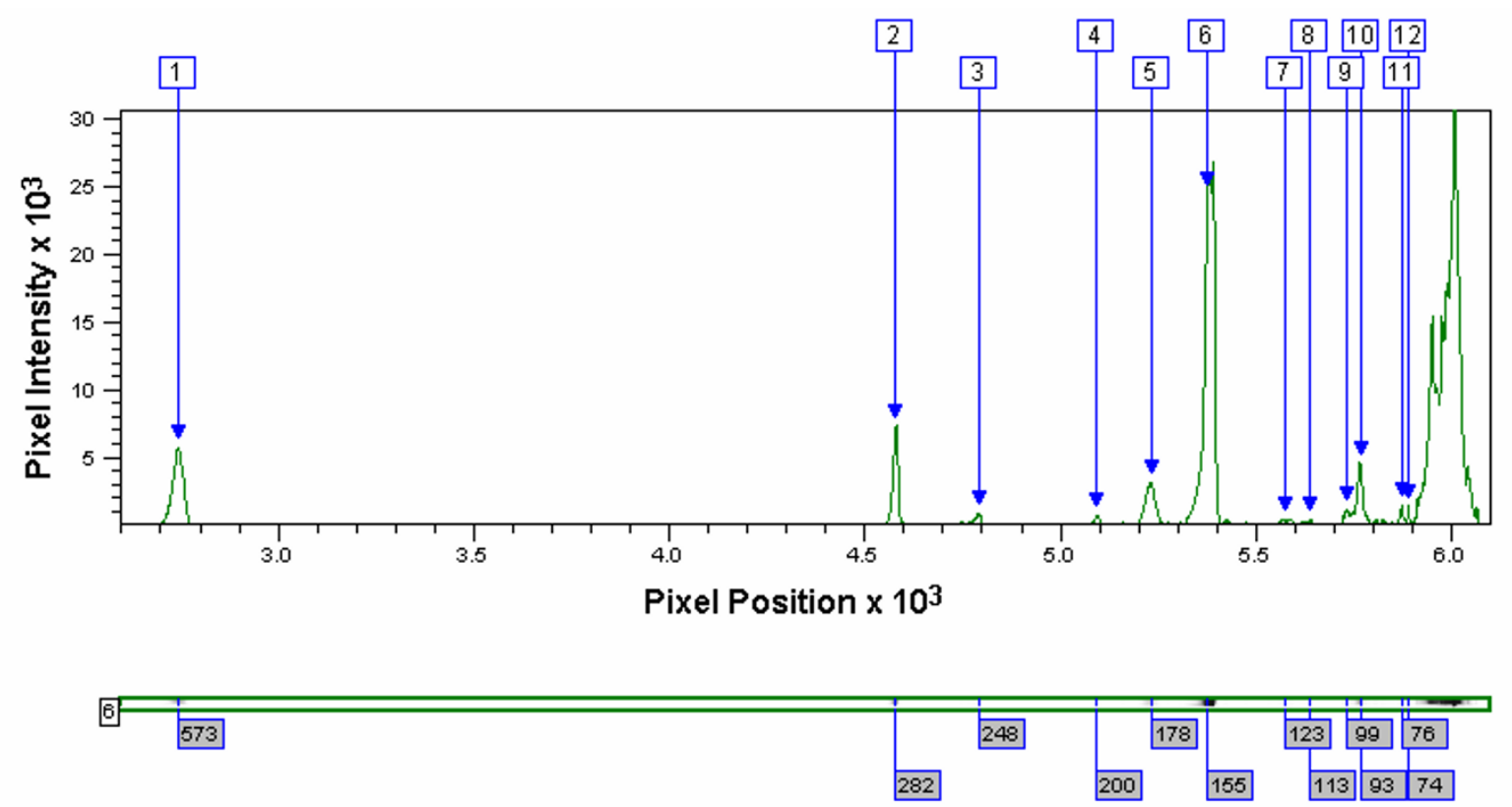

\section{RT-T-RFLP}
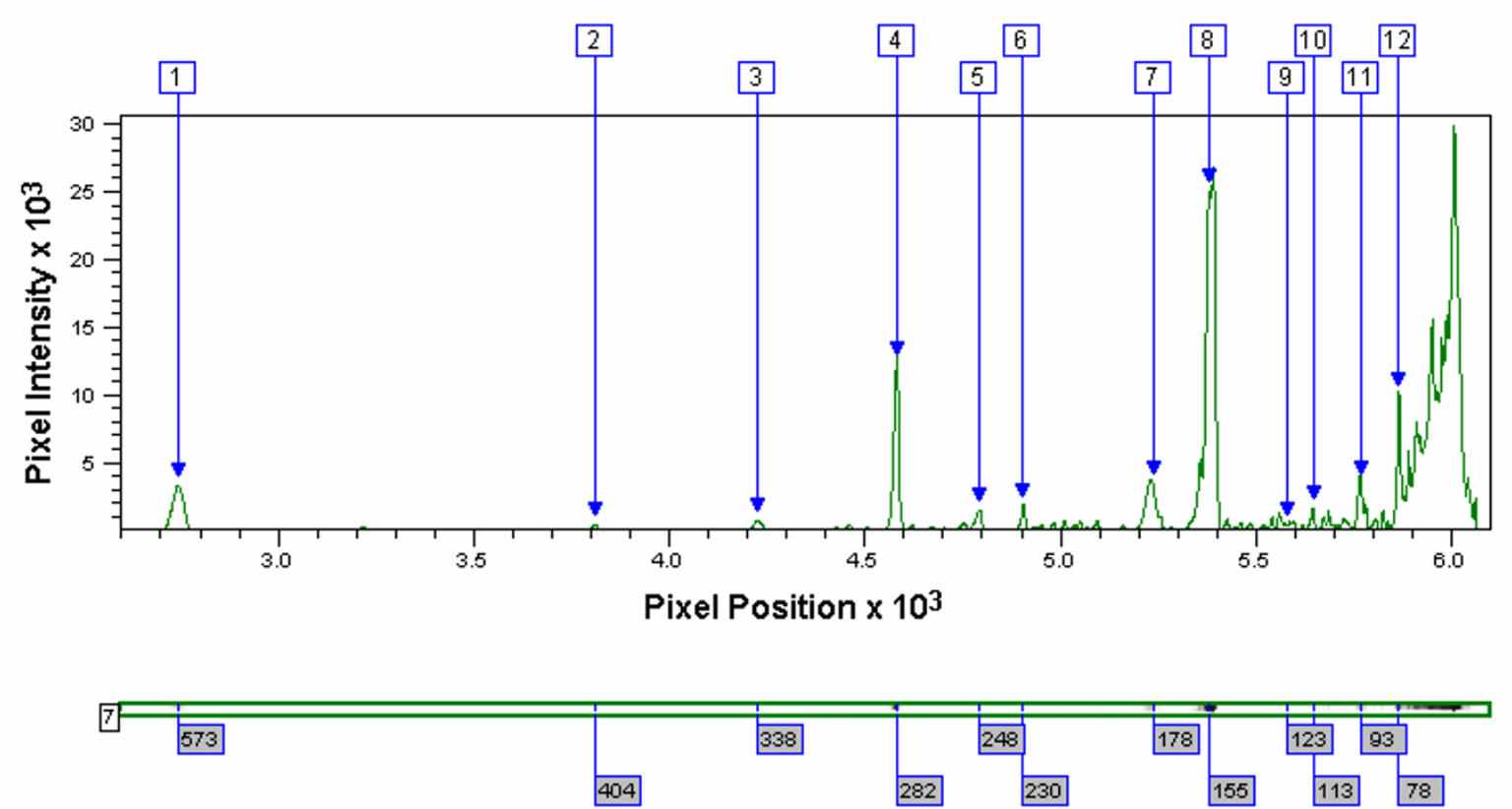

Figure 2

Identification of individual bands within regions of corresponding T-RFLP and RT-T-RFLP profiles. This figure shows regions of profiles as analysed using Phoretix ID Advanced v.5. I0 (Nonlinear Dynamics, Newcastle upon Tyne, UK). In each case, the region of electrophoretic profile is shown (below) next to a trace of relative band intensity. The manual confirmation of correct band identification minimises the inclusion of erroneous peaks. 
Table I: Number of bands detected in T-RFLP and RT-T-RFLP profiles generated from the sample set.

\begin{tabular}{ccc}
\hline Patient & T-RFLP bands & RT-T-RFLP bands \\
\hline 1 & 42 & 33 \\
2 & 35 & 38 \\
3 & 14 & 22 \\
4 & 25 & 27 \\
5 & 38 & 18 \\
6 & 26 & 15 \\
7 & 16 & 21 \\
8 & 13 & 15 \\
9 & 14 & 38 \\
10 & 10 & 11 \\
11 & 7 & 18 \\
12 & 15 & 15 \\
13 & 12 & 11 \\
14 & 17 & 29 \\
15 & 16 & 20 \\
16 & 10 & 38 \\
17 & 13 & 14 \\
Total & $\mathbf{3 2 3}$ & $\mathbf{3 8 3}$ \\
Average & $19.0(\mathbf{1 0 . 4 )}$ & $\mathbf{2 2 . 5}(\mathbf{9 . 5})$
\end{tabular}

The number of T-RF bands detected above a threshold of $0.1 \%$ of the total lane signal volume is shown for both the T-RFLP and RT-T-RFLP profiles generated from each of the 17 samples. Standard deviations for average values are shown in brackets.

\section{Hierarchical cluster analysis}

A dendrogram was derived by hierarchical cluster analysis using the Dice measure for all of the T-RFLP and RT-TRFLP generated profiles (Figure 3). This showed that for the majority (13 of 17) patients studied, the T-RFLP and RT-T-RFLP profiles from the same sample clustered more closely than any other profile. However, profiles were observed in two instances that more closely matched those of other individuals (patients 3 and 9 and patients 1 and 16, Figure 3).

\section{Healthy, non-CF samples}

Between 18 and 54 individual T-RF bands were detected in the T-RFLP profiles generated from the healthy, non CF sputa. On average $29( \pm 10) \mathrm{T}-\mathrm{RF}$ bands were detected in each profile.

A total of 556 individual T-RF bands were resolved in the 19 samples analysed. These represented 210 different T-RF band lengths. T-RF bands of a given length were detected in between 1 and 18 of the 19 samples, being detected in 2.65 samples $( \pm 3.67)$ on average. Of these $210 \mathrm{~T}-\mathrm{RF}$ band lengths, 81 were detected in both the CF and non CF sputum profiles, 129 were detected in the healthy sample set only, and 114 were detected in the CF only.
Profiles generated from healthy sputum were more similar than profiles generated from CF sputum, with a greater level of overlap between the T-RF bands lengths detected in the profiles generated. In the CF sample set, no T-RF band length was detected in more than $41.1 \%$ of profiles, with $39 \%$ of T-RF band lengths detected in a single profile only, and $22.2 \%$ of T-RF band lengths detected in two profiles, only. By comparison, only $21.9 \%$ and $12.2 \%$ of T-RF band lengths were detected in one or two healthy sputum profiles respectively. Further, 14 different T-RF band lengths were detected in $50 \%$ or more of healthy profiles and 4 were detected in more that $75 \%$ of healthy profiles.

Of the $14 \mathrm{~T}$-RF band lengths detected in $50 \%$ or more of healthy sample profiles, 5 were not detected in the CF sample set at all, 3 were detected in a single sample only, two were detected in two profiles, two in three profiles, one in four profiles and one in 6 profiles.

None of the profiles generated from healthy sputa were found to contain T-RF bands of lengths corresponding to the recognised CF pathogens $P$. aeruginosa, B. cepacia complex, S. aureus, or $H$. influenzae. A T-RF band of 214 bases was resolved in 5 of the 19 healthy profiles. This is consistent with the T-RF band produced by both five different species (Stenotrophomonas maltophilia, Fusobacterium gonidoformans, Aeromonas hydrophila, Shewanella alga, Vibrio wodanis), of which Stenotrophomonas maltophilia is a recognised CF pathogen.

Of the 209 band lengths detected in the RT-T-RFLP profiles, $118(56.4 \%)$ were not detected in the profiles generated from the healthy sputum sample set whatsoever.

Hierarchical cluster analysis, using Dice similarity measure, was performed on the T-RFLP profiles generated from $\mathrm{CF}$ and non-CF samples. The dendrogram that was generated is shown in Figure 4. It was found that there was complete separation of cluster groupings between $\mathrm{CF}$ and nonCF samples.

\section{Discussion}

This study addresses important questions about the activity of bacteria in infections. Recently, it has been shown that many bacterial species not previously associated with CF lung infections, could be detected when molecular biological approaches were applied to the study of sputa $[10,19]$. These studies also showed that many species in CF sputum were facultative or obligate anaerobes. This study shows that the majority of these species were metabolically active. Potentially, this has important implications for treatment and it is now critical to determine what impact these species have on lung disease and to identify their clinical significance. 


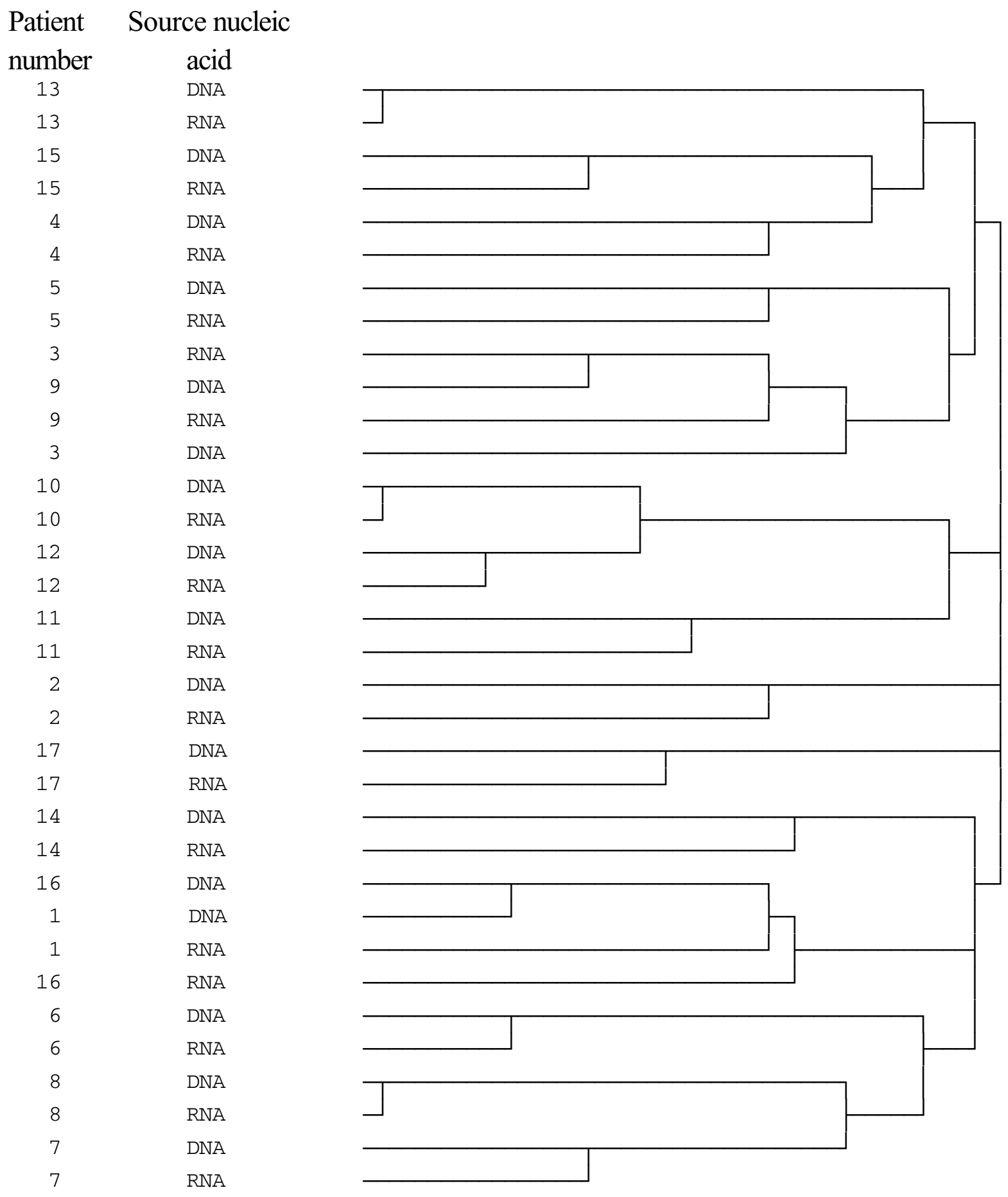

\section{Figure 3}

Dendrogram constructed using T-RFLP and RT-T-RFLP profiles generated from the sample set. A dendrogram was constructed using the results of Hierarchical Cluster Analysis (HCA), using Dice measure, of the T-RFLP and RT-T-RFLP profile data. HCA results in the formation of clusters in which profiles are iteratively joined in a descending order of similarity. 


$$
\begin{array}{ll}
\mathrm{CF} & 16 \\
\mathrm{CF} & 17 \\
\mathrm{CF} & 5 \\
\mathrm{CF} & 14 \\
\mathrm{CF} & 7 \\
\mathrm{CF} & 8 \\
\mathrm{CF} & 2 \\
\mathrm{CF} & 6
\end{array}
$$

Healthy 6

Healthy 7

Healthy 4

Healthy 5

Healthy 2

Healthy 3

Healthy 1

Healthy 11

Healthy 12

Healthy 9

Healthy 10

Healthy 8

Healthy 13

Healthy 14

Healthy 16

Healthy 15

Healthy 17

Healthy 18

Healthy 19

CF 1

CF 11

CF 10

CF 12

CF 3

$\mathrm{CF} 4$

CF 9

CF 13

CF 15

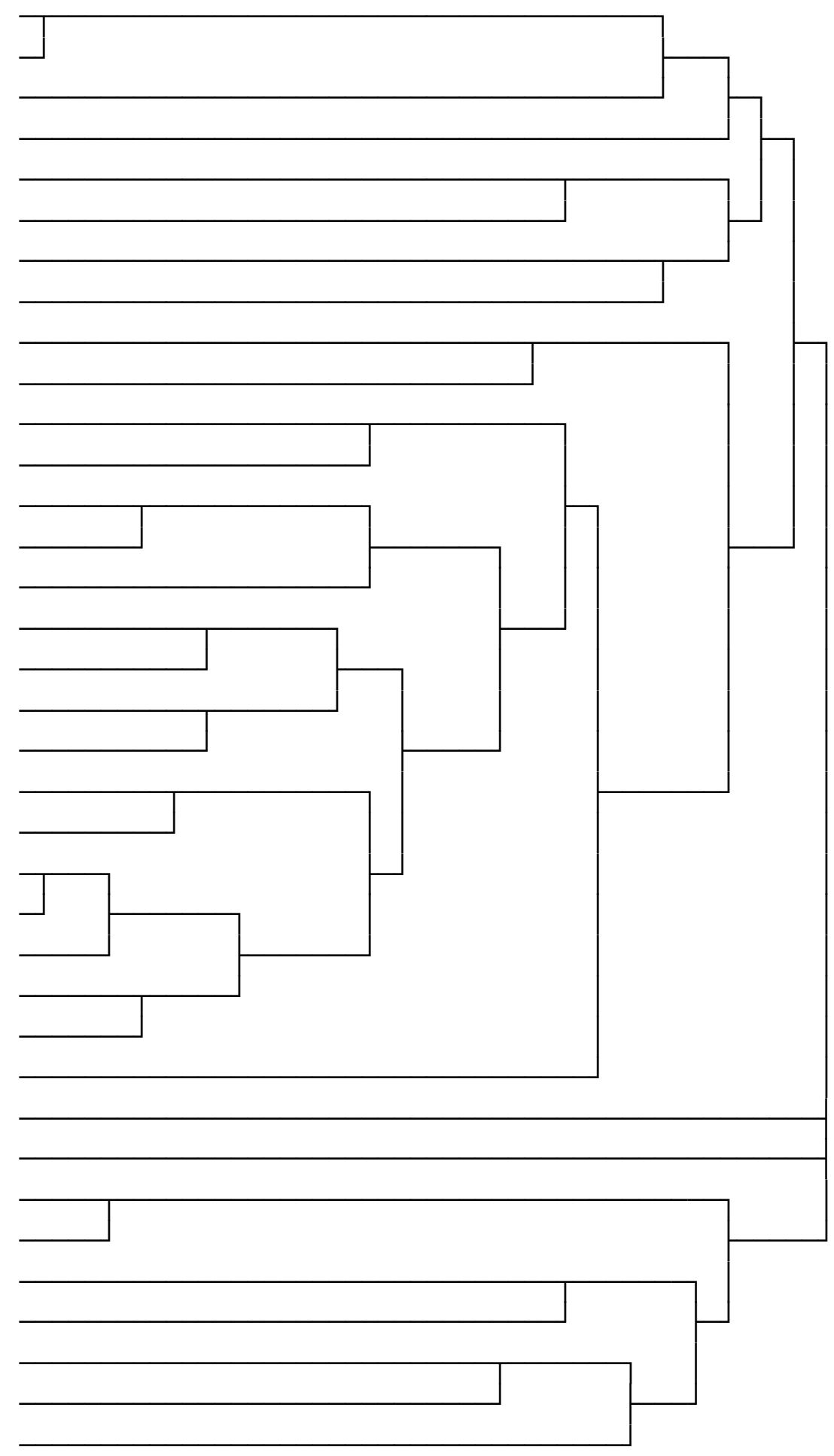

\section{Figure 4}

Dendrogram constructed using T-RFLP profiles generated from sputum samples obtained from CF patients and healthy individuals. A dendrogram was constructed using the results of Hierarchical Cluster Analysis (HCA), using Dice measure, of the T-RFLP profile data. 
The application to clinical studies of the combined approaches used here is novel. These approaches are robust and have previously been shown to be highly reproducible [data not shown, $[10,12]]$. Here it was found that, on average, each patient had more than 22 metabolically active bacterial species per sputum sample. This represented a statistically significant difference over species number identified through T-RFLP alone $(\mathrm{P} \leq 0.001)$. This finding makes it important to determine the role of metabolically active bacteria in lung pathogenesis. Some species may emerge as frank pathogens. However, even active bacterial species that might be considered "avirulent" may play an important indirect role; for example, it has been demonstrated that avirulent oropharyngeal flora can cause an upregulation of virulence genes and consequentially pathogenicity of $P$. aeruginosa $[20]$.

In certain cases, the T-RFLP profile and RT-T-RFLP profile were found by visual comparison to be similar. To provide a more robust analysis, Hierarchical Cluster Analysis (HCA) was used. HCA demonstrated that there was typically greater similarity between profiles generated from individual samples than any other individual. This implies that each patient has an individual collection of typically active bacteria. The lack of HCA clustering according to technique - i.e. discrete groups of T-RFLP profiles and RT-T-RFLP profiles - suggests that the same groups of species are not either "present" or "active" in different individuals. This reinforces the requirement for management to be highly specific for each individual patient, a concept that up to now has been put into practice based on clinical experience without particular scientific backing. Moreover, it may explain the differential response of patients, at apparently similar stages of CF lung disease, to antibiotic regimes.

Marked differences in T-RFLP and RT-T-RFLP profiles were however observed in many cases. For example, in 39.6\% of banding positions, a signal was detected in the RT-TRFLP profile, but not in the corresponding T-RFLP profile. This was not artefactual - there was no significant difference in the overall distribution of the total lane volume in the profiles generated by T-RFLP and RT-T-RFLP profiling. In the case of a signal not being detected in the corresponding T-RFLP profile, it is likely that cells of an individual species were present in low numbers, but exhibited very high metabolic rates. When assessing relative levels of metabolic activity, it should be noted the number of ribosomal gene operons in different bacterial species varies. For example, Rickettsia prowazekii and Mycoplasma pneumoniae have only one ribosomal operon [21,22], whereas Clostridium paradoxum has 15 ribosomal operons [23]. Therefore, in a diverse bacterial community such as is present in the $\mathrm{CF}$ lung this variation will influence the apparent abundance of individual bands in T-RFLP pro- files. The impact of this phenomenon on T-RFLP profiles has yet to be determined as many bands have no species assignation currently (only 18\% of T-RF band lengths match a band length generated from published sequence data). Moreover, even if all bands were associated with individual species, currently just over one hundred species [24] have been fully sequenced. Iteratively, this will become less problematic as more band-species linkages and genome sequences become available.

In the case of bands not being detected in the corresponding RT-T-RFLP analysis, it is likely that these bacteria were either dead or active at very low metabolic rates. The identification of bands in RT-T-RFLP profiles but absent in the corresponding T-RFLP profile from the same sample therefore suggests that these species are highly active but present in numbers below the threshold of detection. The most interesting such case was the identification of a band corresponding to B. cepacia complex, a known CF pathogen, in RT-T-RFLP profiles but not the corresponding TRFLP profiles. This suggests that $B$. cepacia complex is present in relatively low numbers, but is highly metabolically active. Compared to $P$. aeruginosa, B. cepacia complex infects only a small proportion of CF patients, but its impact on survival is significant [25]. Further, the clinical outcome of CF patients colonised by B. cepacia complex is much poorer following lung transplantation than their non-infected counterparts $[26,27]$. For these reasons, the detection of strains of $B$. cepacia complex using these approaches will therefore be carefully monitored in future studies.

The lungs of all individuals are exposed to transient bacteria both that originate both in the oropharyngeal flora and the wider environment. For the detection of such a large number of metabolically active bacterial species in CF sputum to be significant it must be established that they are not due to contamination.

Strenuous attempts were made when processing the sputum samples analysed here to remove bacteria that may have adhered to the sputum bolus during its passage through the upper airways. Further comparisons between the bacterial populations found in CF sputa with those found in mouthwashes obtained from the same patients (data not shown) suggest that there is no significant crosscontamination. Further, here we have analysed the bacterial communities found in sputum obtained from healthy, non-CF individuals. It was found that the majority of the metabolically active bacterial species detected in the CF sputa were not detected at all in non-CF sputa and that bacterial profiles generated from healthy individuals show both a high degree of conservation, and a distinct dissimilarity to those generated from CF sputa. Further, the detection of metabolically active bacterial species in 
both CF sputum and either CF oropharyngeal community or non-CF sputum is not necessarily an indication of contamination. Bacterial species colonising the $\mathrm{CF}$ lung almost certainly derive from either transient bacterial species to which we are all exposed, or to oropharyngeal flora. Therefore, their presence in sputum may well indicate genuine lung colonisation.

Like any other novel approach, data interpretation must be carried out with caution. However, more studies using this and complementary approaches will build upon this characterisation of the complex bacterial community colonising the CF lung. Moreover, this approach can be applied to many other infectious diseases of single or polymicrobial origin. Other diagnostic systems such as gene array applications have clear diagnostic potential [reviewed in [28]]. By their nature however, they can only detect signature sequences for bacteria that have been deposited on the supporting matrix and are, therefore, "closed" systems. The RT-T-RFLP approach that we describe here is an open system where no prior assumptions have been made about the species present in the clinical sample and may, as such, be more flexible. For diagnosis, the RT-T-RFLP system will be developed through the construction of a large database containing digest patterns for individual species. In turn, this will provide clinicians with diagnostic identifications tied to probability value scores. This process translates into more rapid detection - providing results in hours rather than days. This can be equated easily to cost savings in terms of operator time and, where relevant, hospital bed occupancy. Also, there are benefits in terms of more appropriate drug selection. Apart from likely cost savings, this will be particularly important in reducing the impact of long term antibiotic use on patients e.g. renal damage.

The RT-T-RFLP system can offer flexibility in other ways. By switching the PCR primers used, it has the potential to reveal diagnostic information at either the sub-species level, or for fungal or viral infections. Moreover, RT-TRFLP system can be coupled with Quantitative PCR techniques [29]. With development, RT-T-RFLP has the potential to rapidly assess treatment efficacy by monitoring bacterial viability within clinical samples taken from an individual patient. This monitoring would provide clinicians with data with which to make informed decisions e.g. on dosage modifications or more profound alterations in therapy. Through such studies, this may provide fresh insights into the process of infection in a wide range of respiratory diseases.

\section{Conclusion}

Overall, this study has shown that the majority of bacterial species detected and previously reported in CF lung infections are metabolically active. Further, this suggests that the majority of species detected in samples from the $\mathrm{CF}$ lung may play important roles in lung infections. The roles of these bacteria in the pathogenic process occurring in the CF lung are therefore worthy of much further investigation. Moreover, this approach may prove very valuable clinically in the study of many other microbial infections.

\section{Authors' contributions}

All authors participated in the conception and design of the study. GB Rogers carried out all experimental procedures and data analysis. Work was coordinated by KD Bruce. All authors read and approved the final manuscript.

\section{Additional material}

\section{Additional File 1}

Table 2. T-RF band lengths and percentages of total lane signal volume. The length in bases and the relative proportion of the total lane signal volume (\% total) of each of the T-RF bands detected in the T-RFLP and RT-T-RFLP profiles generated from the samples.

Click here for file

[http://www.biomedcentral.com/content/supplementary/14659921-6-49-S1.xls]

\section{Acknowledgements}

We wish to acknowledge Jackie Hunt, Andy Tuck and members of the Adult CF Unit, Southampton General Hospital for their helpful advice and assistance. We wish also to acknowledge the King's College London and the Cystic Fibrosis Trust (CSIG grant) for funding that supported this work.

\section{References}

I. Horner-Devine MC, Carney KM, Bohannan BMJ: An ecological perspective on bacterial biodiversity. Proc Roy Soc London Ser BBiol Sci 2004, 27 I : I I3- I 22.

2. Keer JT, Birch L: Molecular methods for the assessment of bacterial viability. J Microbiol Meth 2003, 53: I75-I83.

3. Torsvik V, Ovreas L: Microbial diversity and function in soil: from genes to ecosystems. Curr Opin Microbiol 2002, 5:240-245.

4. Liesack W, Stackebrandt E: Occurrence of novel groups of the Domain Bacteria as revealed by analysis of genetic material isolated from an Australian terrestrial environment. J Bacteriol 1992, I 74:5072-5078.

5. Liu WT, Marsh TL, Cheng H, Forney LJ: Characterization of microbial diversity by determining Terminal Restriction Fragment Length Polymorphisms of genes encoding I6S rRNA. Appl Environ Microbiol 1997, 63:4516-4522.

6. McCormick J, Green MW, Mehta G, Culross F, Mehta A: Demographics of the UK cystic fibrosis population: implications for neonatal screening. Eur J Hum Genet 2002, I 0:583-90.

7. Lewis PA, Morison S, Dodge JA, Geddes D, Coles EC, Russell G, Littlewood JM, Scott MT: Survival estimates for adults with cystic fibrosis born in the United Kingdom between 1947 and 1967. Thorax 1999, 54:420-422.

8. Lyczak JB, Cannon CL, Pier GB: Lung infections associated with cystic fibrosis. Clin Microbiol Rev 2002, I 5:194-222.

9. Kolak M, Karpati F, Monstein HJ, Jonasson J: Molecular typing of the bacterial flora in sputum of cystic fibrosis patients. Int J Med Microbiol 2003, 293:309-I7.

10. Rogers GB, Hart CA, Mason JR, Hughes M, Walshaw MJ, Bruce KD: Bacterial diversity in cases of lung infection in cystic fibrosis patients: I 6S ribosomal DNA (rDNA) length heterogeneity 
PCR and I6S rDNA terminal restriction fragment length polymorphism profiling. J Clin Microbiol 2003, 4I:3548-3558.

II. van Belkum A, Renders NH, Smith S, Overbeek SE, Verbrugh HA: Comparison of conventional and molecular methods for the detection of bacterial pathogens in sputum samples from cystic fibrosis patients. FEMS Immunol Med Microbiol 2000, 27:5I-57.

12. Rogers GB, Carroll MP, Serisier DJ, Hockey PM, Jones G, Bruce KD: Characterization of Bacterial Community Diversity in Cystic Fibrosis Lung Infections Using I6S rDNA Terminal Restriction Fragment Length Polymorphism Profiling. J Clin Microbiol in press.

13. Brook I, Fink R: Transtracheal aspiration in pulmonary infection in children with cystic fibrosis. Eur J Resp Dis 1983, 64:5I-57.

14. Jewes LA, Spencer RC: The incidence of anaerobes in the sputum of patients with cystic fibrosis. J Med Microbiol 1990, 3I:27I-274.

15. Costerton JW, Stewart PS, Greenberg EP: A Common Cause of Persistent Infections. Science 1999, 284:|3| 8-1322.

16. Wagner M, Assmus B, Hartmann A, Hutzler P, Amann R: In situ analysis of microbial consortia in activated sludge using fluorescently labelled, rRNA-targeted oligonucleotide probes and confocal scanning laser microscopy. J Microsc 1994, I 76: 181-7.

17. Cashel M, Rudd KE: The stringent response. In Escherichia coli and Salmonella typhimurium: cellular and molecular biology Volume 2. Edited by: Neidhardt FC, Ingraham JL, Low KB, Magasanik B, Schaechter M, Umbarger HE. American Society for Microbiology, Washington, DC; 1987:| |410-1438.

18. Lüdemann H, Arth I, Liesack W: Spatial Changes in the Bacterial Community Structure along a Vertical Oxygen Gradient in Flooded Paddy Soil Cores. Appl Environ Microbiol 2000, 66:754-762.

19. Coenye T, Goris J, Spilker T, Vandamme P, LiPuma J]: Characterization of unusual bacteria isolated from respiratory secretions of cystic fibrosis patients and description of Inquilinus limosus gen. nov., sp nov. J Clin Microbiol 2002, 40:2062-2069.

20. Duan K, Dammel C, Stein J, Rabin H, Surette MG: Modulation of Pseudomonas aeruginosa gene expression by host microflora through interspecies communication. Mol Microbiol 2003, 50:1477-|49|.

21. Anderson SG, Zomorodipour A, Winkler HH, Kurland CG: Unusual organisation of the rRNA genes in Rickettsia prowazekii. J Bacteriol 1995, 177:4171-4I75.

22. Bercovier H, Kafri O, Sela S: Mycobacteria possess a surprisingly small number of ribsomal RNA genes in relation to the size of their genome. Biochem Biophys Res Commun 1986, I36: I|36-||4|.

23. Rainey FA, Ward-Rainey NL, Janssen PH, Hippe H: Clostridium paradoxum DSM 7308(T) contains multiple 16S rRNA genes with heterogenous intervening sequences. Microbiology 1996, I 42:2087-2095.

24. Centre for Biological Sequence Analysis, Technical University of Denmark [http://www.cbs.dtu.dk]. (accessed July 19th, 2004)

25. Liou TG, Adler FR, Fitzsimmons SC, Cahill BC, Hibbs JR, Marshall BC: Predictive 5-year survivorship model of cystic fibrosis. Am J Epidemiol 200I, 153:345-352.

26. Aris RM, Routh JC, LiPuma JJ, Heath DG, Gilligan PH: Lung transplantation for cystic fibrosis patients with Burkholderia cepacia complex: survival linked to genomovar type. Am J Respir Crit Care Med 2001, 164:2102-2106.

27. LiPuma JJ: Burkholderia cepacia complex: a contraindication to lung transplantation in cystic fibrosis? Transpl Infect Dis 200I, 3:149-160.

28. Raoult $\mathrm{D}$, Fournier PE, Drancourt $\mathrm{M}$ : What does the future hold for Clinical Microbiology? Nature Rev Microbiol 2004, 2: I5I-I59.

29. Harris KA, Hartley JC: Development of broad-range I6S rDNA PCR for use in the routine diagnostic Clinical Microbiology service. J Med Microbiol 2003, 52:685-69l.

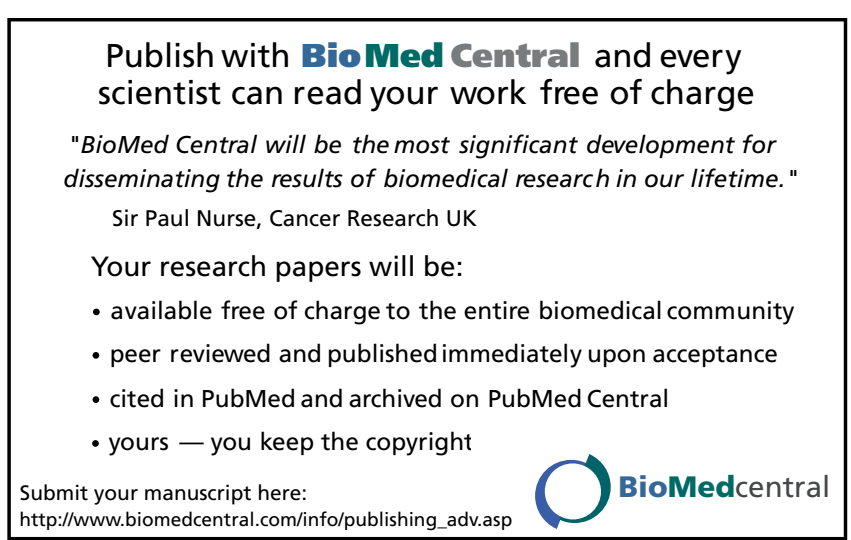

